\title{
Blockade of Rho-associated protein kinase (ROCK) inhibits the contractility and invasion potential of cancer stem like cells
}

\author{
Srisathya Srinivasan ${ }^{1, *}$, Vandhana Ashok ${ }^{1, *}$, Sagarajit Mohanty ${ }^{1}$, Alakesh Das ${ }^{1}$, \\ Sreya Das ${ }^{1}$, Sushant Kumar ${ }^{1}$, Shamik Sen ${ }^{1}$, Rahul Purwar ${ }^{1}$ \\ ${ }^{1}$ Department of Biosciences \& Bioengineering, Indian Institute of Technology Bombay (IIT Bombay), Mumbai, Maharashtra, \\ India \\ *These authors have contributed equally to this work \\ Correspondence to: Rahul Purwar, email: purwarrahul@iitb.ac.in \\ Shamik Sen, email: shamiks@iitb.ac.in \\ Keywords: ROCK pathway, cancer stem cells, cell contractility, invasion, metastasis
}

Received: October 15, 2016

Accepted: January 17, 2017

Published: February 10, 2017

\section{ABSTRACT}

Recent studies have implicated the roles of cancer stem like cells (CSCs) in cancer metastasis. However, very limited knowledge exists at the molecular and cellular level to target CSCs for prevention of cancer metastasis. In this study, we examined the roles of contractile dynamics of CSCs in cell invasion and delineated the underlying molecular mechanisms of their distinct cell invasion potential. Using de-adhesion assay and atomic force microscopy, we show that CSCs derived from melanoma and breast cancer cell lines exhibit increased contractility compared to non-CSCs across all tumor types. In addition, CSCs possess increased ECM remodeling capacity as quantified by collagen degradation assay. More importantly, pharmacological blockade of Rho-associated protein kinase completely abolished the contractility and collagen degradation capacity of both CSCs and non-CSCs. In conclusion, our study demonstrates the importance of cell contractility in regulating invasiveness of CSCs and suggests that pharmacological targeting of ROCK pathway represents a novel strategy for targeting both CSCs and bulk population for the treatment of cancer metastasis.

\section{INTRODUCTION}

Although surgical removal of primary tumors is effective in treating localized tumors, treating cancer metastasis remains a formidable challenge. Recent studies have described the roles of cancer stem cells (CSCs) in cancer metastasis [1-5]. Therefore, it is critical to target CSCs and tumor bulk population for long-term cancer remission. However, there exists limited knowledge of therapeutic targets, which can be used for targeting CSCs along with bulk population for the treatment of cancer metastasis.

Cancer metastasis is a multi-step process and involves several biochemical and biophysical cues of the tumor cells. Contractile dynamics of a tumor cell represents one of the most important biophysical properties that regulates metastasis and invasion ability [6], and is closely associated with cell spreading and cell adhesion properties [7]. Increased cell contractility in breast cancer is associated with cell invasion through dense interstitial matrices by allowing cells to squeeze through matrix pores and also in intravasation and extravasation [8]. We, and others have previously demonstrated a close relationship between cell contractility and invasiveness in breast cancer cell line (MDA-MB-231), ovarian cancer cell lines including OVCAR3 and SKOV3 and melanoma cells [9-12]. Additionally, pancreatic cell lines with higher contractility secrete increased levels of matrix metalloproteases (MMPs) and show higher invasion capacity [13]. However, it remains unknown if biophysical characteristics, especially contractile dynamics of CSCs are distinct compared to the bulk tumor population and contribute in CSC mediated cell invasion.

Cell contractility is mediated mainly by the acto-myosin machinery, and is generated by myosin II sliding along actin filaments [14]. Several studies have demonstrated that tumor cells having defective myosin bundles are deformed easier than normal cells $[15,16]$. Myosin II activity is regulated by two groups of enzymes including myosin light chain kinase (MLCK) and Rho- 
associated protein kinase (ROCK), both of which phosphorylate myosin light chain (MLC). In addition, ROCK inhibits phosphatase activity [17].

Though contractile dynamics of tumor cells is regulated by ROCK pathway, its role in contractility and cell invasion potential of CSCs in various cancer has not yet been examined. In this study, we examined the invasion potential of CSCs, focusing on their contractile dynamics and ECM remodeling, to identify the novel pathway for targeting CSCs. We demonstrate higher contractile dynamics of CSCs compared with non-CSCs using trypsin de-adhesion assay, which we established earlier for probing contractile mechanics of adherent cells [7], and by atomic force microscopy (AFM). Interestingly, CSCs showed increased collagen degradation potential compared to the control population (parental cells). Importantly, pharmacological blockade of ROCK pathway led to inhibition of contractility and collagen degradation ability of both CSCs and non-CSCs across cancer types. In conclusion, pharmacological targeting of ROCK abrogates the contractility and cell invasion potential of both CSCs and non-CSCs, and is therefore a novel strategy for the treatment of cancer metastasis.

\section{RESULTS}

\section{CSCs show higher contractile dynamics compared to parental cells}

We enriched CSCs from two different breast cancer cell lines (MCF-7 and MDA-MB-231) and a melanoma cell line (MDA-MB-453) using two distinct approaches: Fluorescence activated cell sorting (FACS) and spheroid assay as described in materials and methods.

Because CD $44^{\text {high }} / \mathrm{CD} 24^{-/ \text {low }}$ cells do not represent pan-CSC population, spheroid assay was also used to enrich CSCs [18]. To confirm that the spheroids were enriched with stem like cells, the mRNA levels of stemness genes (Oct4, Nanog and Klf4) were quantified by real time RT-PCR. The spheroids isolated from MCF7 and MDA-MB-453 showed increase in the expression level of Oct4 (5-120 fold), Nanog (4 to 140 fold) and Klf4 (3.5 to 8 fold) (Supplementry Figure 1a).

As contractile dynamics is one of the most critical biophysical properties for the cell invasion potential, CSCs contractility was assessed using the trypsin de-adhesion assay, in which retraction kinetics of individual cells treated with warm trypsin is tracked till cells round up but remain attached to the underlying substrate (Figure 1a) [7]. Both, the CD44 high/CD24-/low cells and the spheroid derived single cells (SDCs) de-adhere faster when compared to the cells from the bulk population, as evident from the representative time-lapse images of MCF-7 (Figure 1b). For quantification of contractile dynamics of CSCs from all cell lines, temporal curves of normalized change in area
$(\bar{A})$ were fitted with the Boltzmann equation to obtain the de-adhesion time constants $\tau_{1}$ and $\tau_{2}$, respectively (Figure 1c-1e). The total de-adhesion time $\left(\tau_{\text {total }}\right)$ was chosen as the sum of the two time constants. In line with the visual observations, statistically significant reduction was observed in the $\tau$ total $\left(\tau_{1}+\tau_{2}\right)$ between parental cells and stem like cells across all cell lines (Figure 1f). Specifically, de-adhesion time ( $\tau$ total) for CD $44^{\text {high }} / \mathrm{CD} 24^{-/ \text {low }}$ and the SDCs of MCF-7 cells was $40 \mathrm{sec}$ and $50 \mathrm{sec}$ respectively compared to $80 \mathrm{sec}$ for parental cells ( $\mathrm{p}$ value $<0.0001$ ). In MDA-MB-453 and MDA-MB-231 cells, almost 50$60 \%$ drop in total de-adhesion time was observed in both $\mathrm{CD} 44^{\text {high }} / \mathrm{CD} 24^{-/ \text {low }}$ cells and the SDCs compared to parental cells ( $p$ value $<0.0001$ ). Collectively, these results demonstrate that CSCs are more contractile compared to the parental population across all cancer cell lines tested.

\section{Contractile dynamics of CSCs is regulated by the ROCK pathway}

Next, we attempted to delineate the mechanisms of increased contractility of CSCs compared with parental cells. Given the higher contractility of stem-like cells (CD44 $4^{\text {high }} / \mathrm{CD} 24^{-/ \text {low }}$ sorted cells and SDCs), we probed the relative contributions of MLCK and ROCK pathways in modulating contractile mechanics using highly specific pharmacological inhibitors (ML7, Y-27632 and Blebbistatin) of MLCK and ROCK pathway (Figure 2a). ML7 (MLCK inhibitor) delayed the de-adhesion dynamics of MCF-7-SDCs compared to vehicle treated controls (Figure 2b). However, treatment with either Y-27632 (ROCK inhibitor) or Blebbistatin (global myosin inhibitor) completely abolished de-adhesion of CSCs of MCF-7 and MDA-MB-453 cells with no observable changes in cell area even after $300 \mathrm{sec}$ (Figure 2c).

In order to examine the effect of the pharmacological agents on the bulk tumor population, parental cells of MCF-7 and MDA-MB-453 cell lines were treated with ML7, Y-27632 and Blebbistatin (Figure 3a-3d). Similar to CSCs, Y-27632 and Blebbistatin treated parental cells showed almost 2-3 fold increase in the de-adhesion time when compared to the vehicle treated sample (Figure 3c$3 \mathrm{~d}$; $\mathrm{p}$ value $<0.0001)$. Overall, these results suggest that the ROCK pathway regulates contractility of CSCs as well as tumor bulk population.

\section{Examining the cortical stiffness of CSCs by atomic force microscopy (AFM)}

Given the close association between cell stiffness and invasiveness, we next probed cortical stiffness of CSCs by atomic force microscopy (AFM) (Figure 4a). Experimental force-indentation curves were fit with Hertz model to obtain estimates of the elastic modulus of the cells (Figure 4b). CSCs obtained from MCF-7 and MDA- 

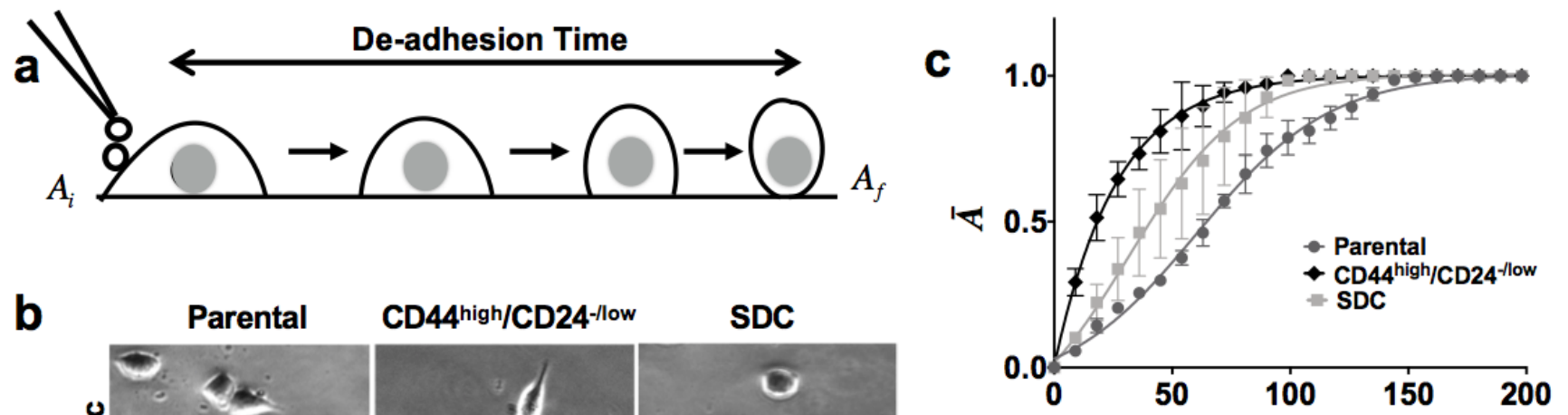

b
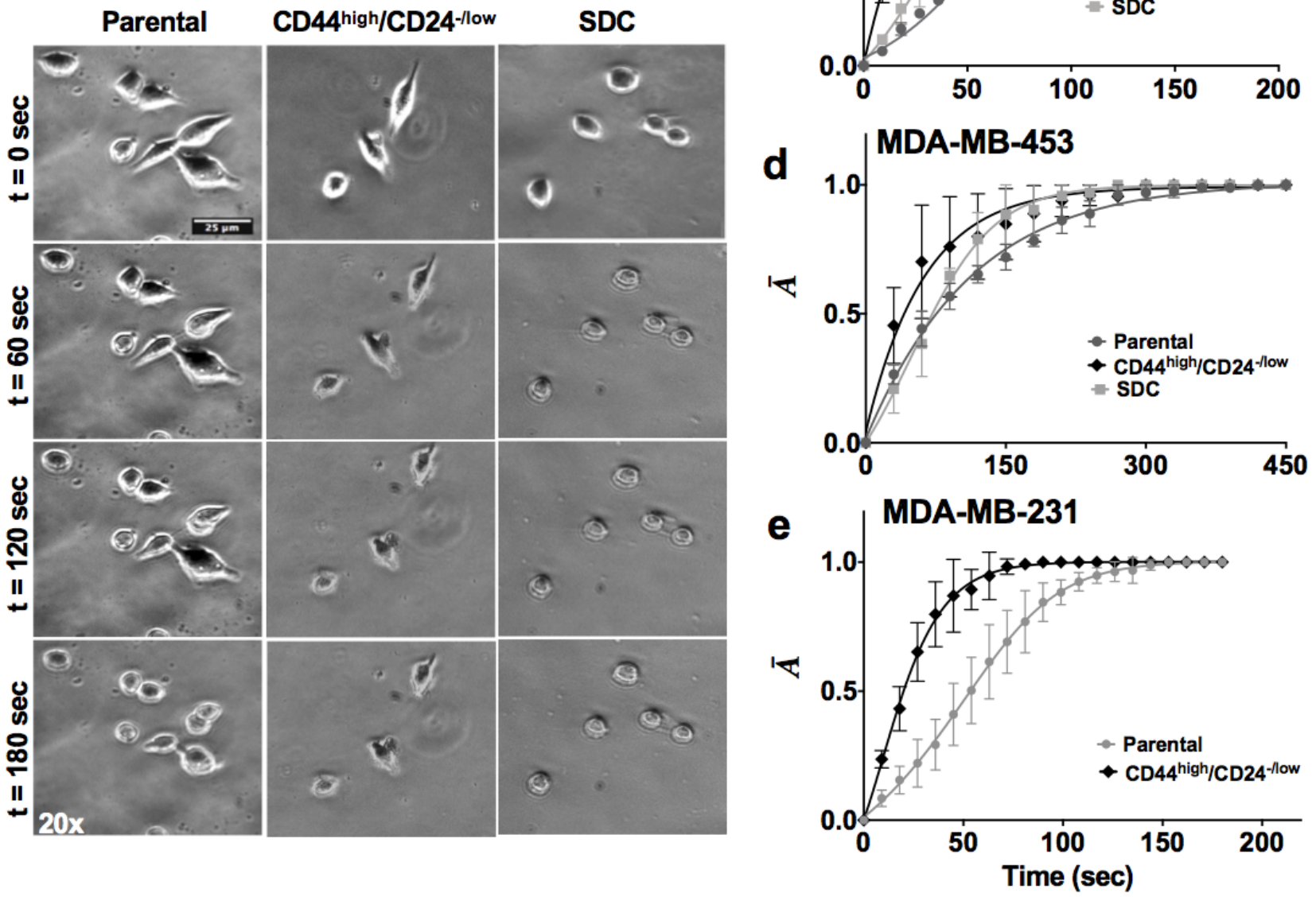

$\mathbf{f}$
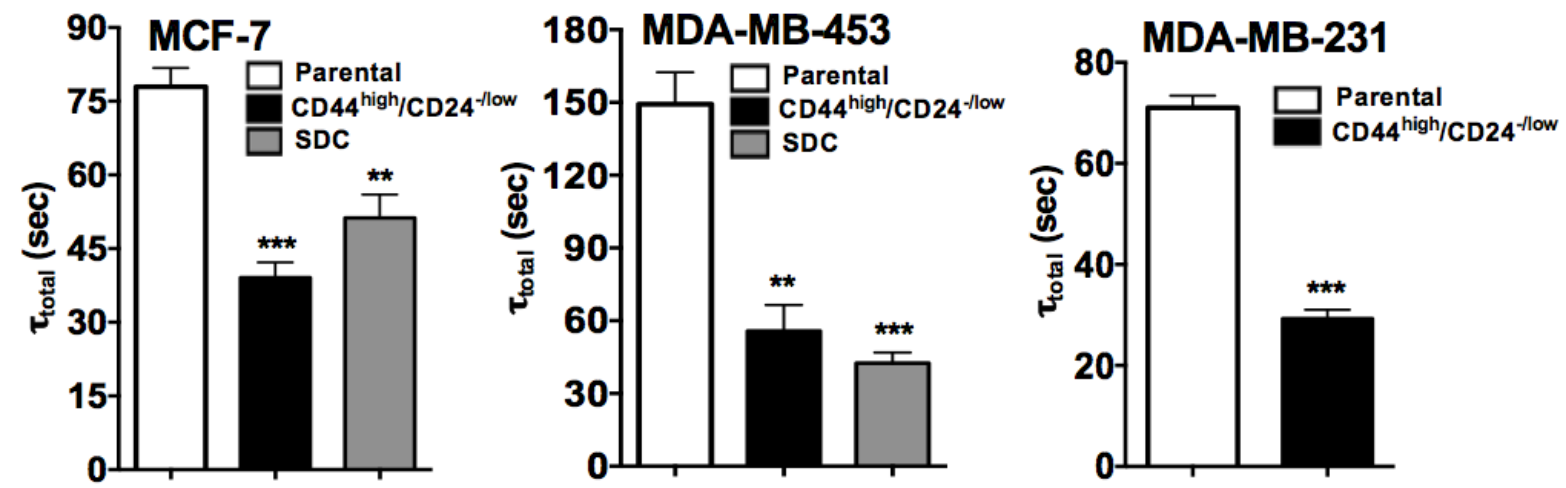

Figure 1: CSCs are more contractile than parental cells. a. Schematic of the trypsin de-adhesion assay. Upon incubation with warm trypsin, adherent cells round up. The de-adhesion process is imaged till cells are completely rounded up but remain attached to their substrates. b. Representative time-lapse image of the de-adhesion dynamics of MCF-7 (parental cells, CD44 ${ }^{\text {high }}$ CD24 ${ }^{-/ \text {low }}$ and SDC cells). Scale bars: 25 microns. c-e. De-adhesion data was quantified by plotting the normalized change in cell area $(\bar{A})$ as a function of time for MCF-7, MDA-MB-453 and MDA-MB-231 CSCs and parental cells respectively. The detachment response was sigmoidal with CSCs like population enriched from all three cell lines showing higher contractility when compared to the parental cells. f. The detachment response curve was fit using the Boltzmann equation to obtain the time constants $\tau_{1}$ and $\tau_{2}$. The total de-adhesion time $\left(\tau_{\text {tonal }}\right)$ was calculated as the sum of $\tau_{1}$ and $\tau_{2}$. Faster de-adhesion dynamics resulted in a significant reduction in the $\tau_{\text {total }}$ for stem-like cells compared to the parental population. $(* * \mathrm{p}<0.001, * * * \mathrm{p}<0.0001)(\mathrm{n}=3)$. Data is represented as Mean $\pm \mathrm{SEM}$ for line graph and Mean $+\mathrm{SEM}$ for bar graph. 
a
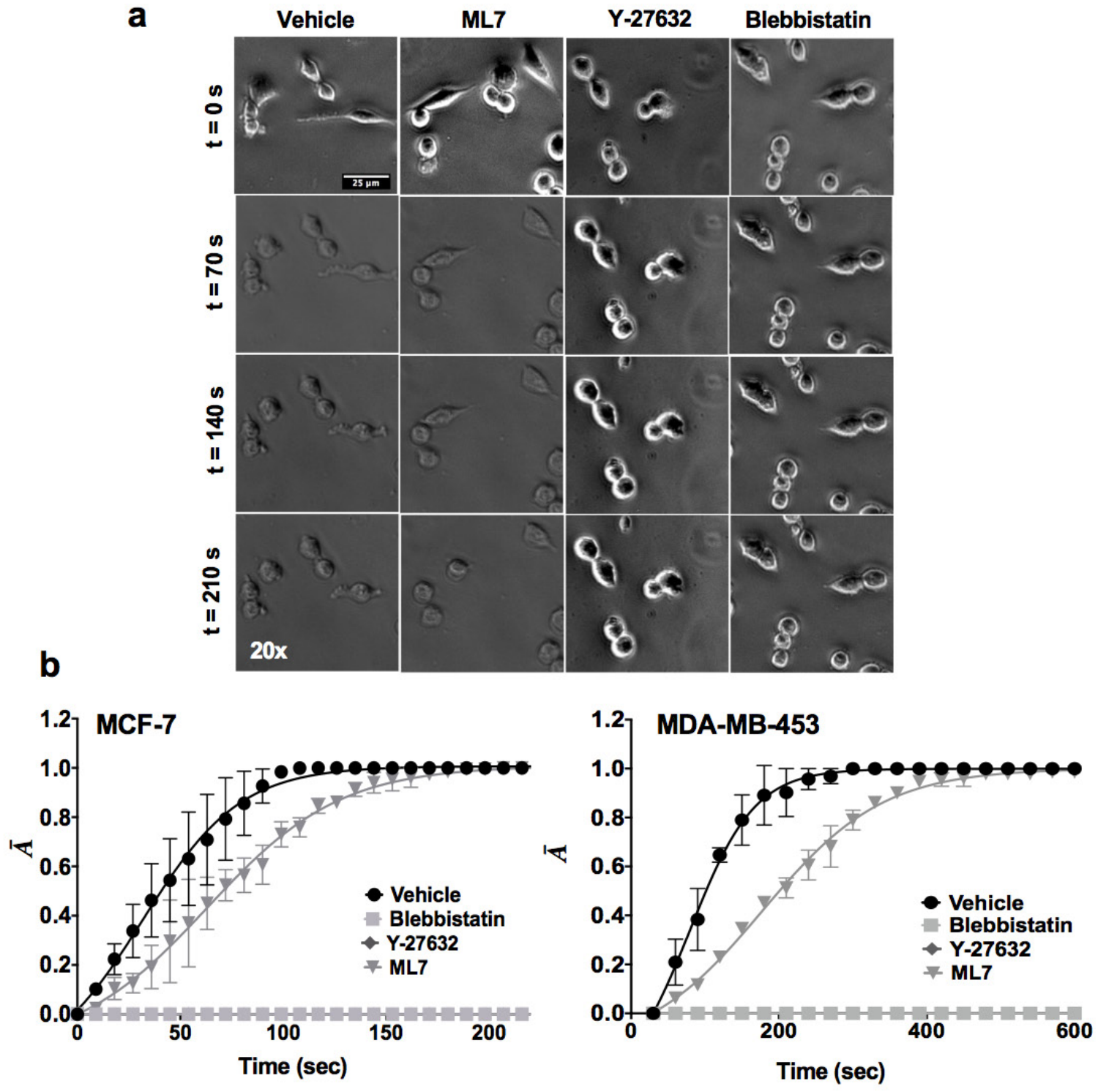

C

MCF-7

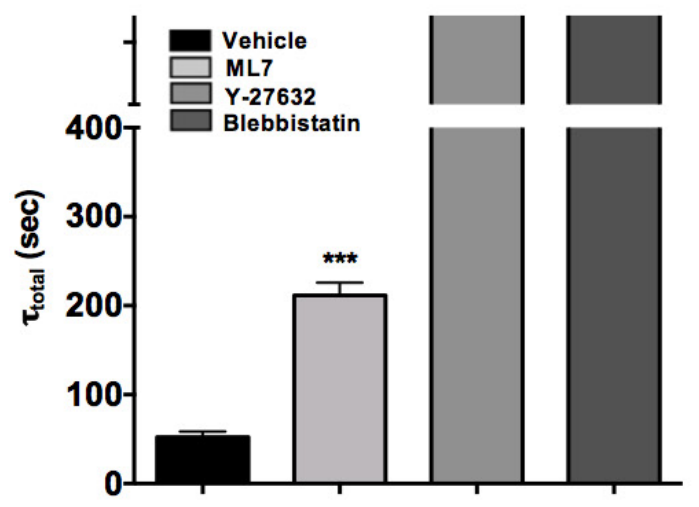

MDA-MB-453

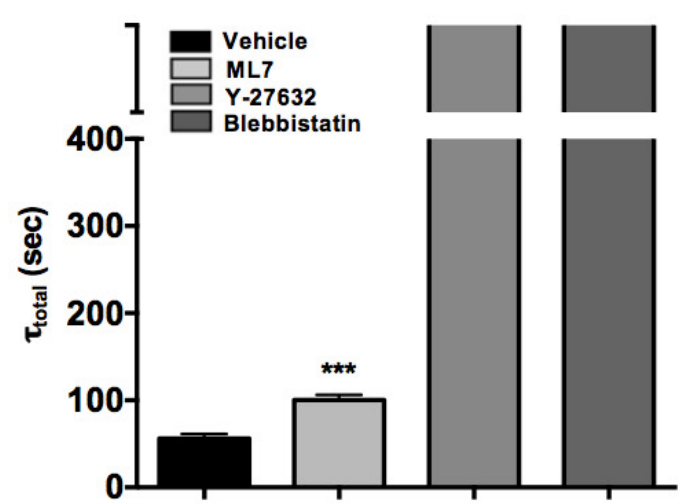

Figure 2: The ROCK pathway plays a dominant role in modulating CSC contractility. a. Representative time-lapse image of spheroid derived single cells (SDC) of MCF-7 cell line treated with contractility inhibiting drugs ML7, Y-27632 and Blebbistatin (Scale bars: 25 microns). b. De-adhesion data of SDCs of MCF-7 and MDA-MB-453 cells treated with Y-27632 and Blebbistatin. c. Quantification of $\tau_{\text {total }}$ in control (vehicle) and drug-treated SDCs from MCF-7 and MDA-MB-453 respectively. (***, p value $\left.<0.0001\right)$ ( $n=20$ cells per condition). Data is represented as Mean \pm SEM for line graph and Mean + SEM for bar graph. 
MB-231 using both methods (sorted CD44 high/CD24-/low and SDCs) were significantly softer than parental cells $(\mathrm{p}<0.05)$. Intriguingly, MDA-MB-453 CSCs obtained from spheroids (SDCs) exhibited higher cortical stiffness $(\mathrm{p}<0.05)$ and sorted $\mathrm{CD} 44^{\text {high }} / \mathrm{CD} 24^{-/ \text {low }} \mathrm{CSC}$ s of MDAMB-453 showed no significant difference in cortical stiffness (Figure 4c).

Next, AFM was performed with CSCs (SDCs) of MDA-MB-453 and MCF-7 cell lines upon treatment with the inhibitors to probe the effects of the MLCK and ROCK pathways on cell stiffness. Y-27632 and Blebbistatin treatment reduced cell stiffness by nearly $50 \%$ in SDCs of MCF-7 and MDA-MB-453, indicating the roles of ROCK pathway in maintaining cell stiffness in both the cell lines (Figure 4d-4e).

\section{CSCs possess increased ECM remodeling potential}

To examine if higher contractile dynamics of CSCs results in increase in invasion potential, we analyzed the ECM remodeling potential of CSCs and parental cells by the collagen degradation assay. CSCs (sorted CD $44^{\text {high }} / \mathrm{CD} 24^{-/ \text {low }}$ cells) and parental cells were seeded on fluorescently tagged collagen-coated glass coverslips and relative degradation of the collagen compared to the cell area was quantified (Figure 5a). Significantly higher level of degradation was observed in CSCs compared to the control (parental cells) in MDA-MB-453 (2.5 fold increase, $\mathrm{p}$ value $<0.0001$ ) and MDA-MB-231 (1.5 fold increase, $\mathrm{p}$ value $<0.0001)$. Cells sorted from MCF-7 did

\section{a}
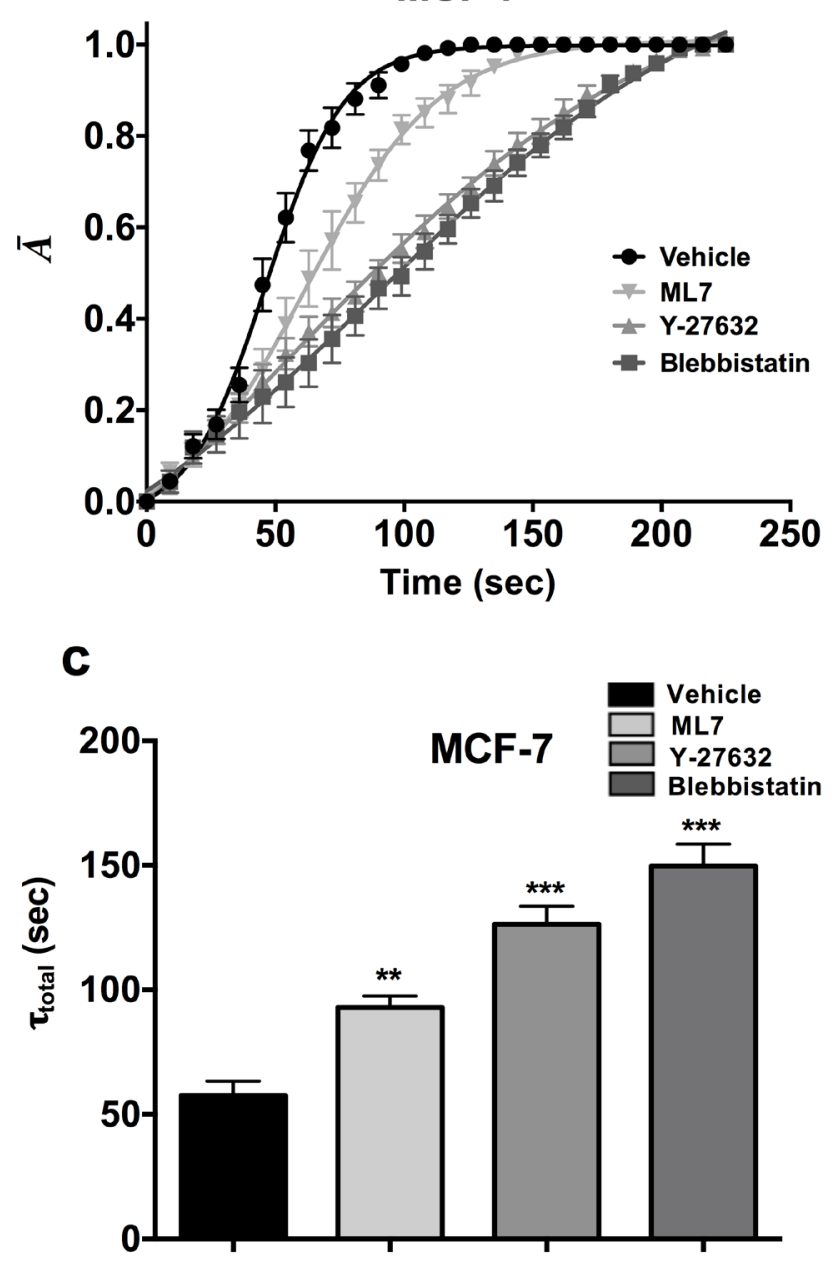

b
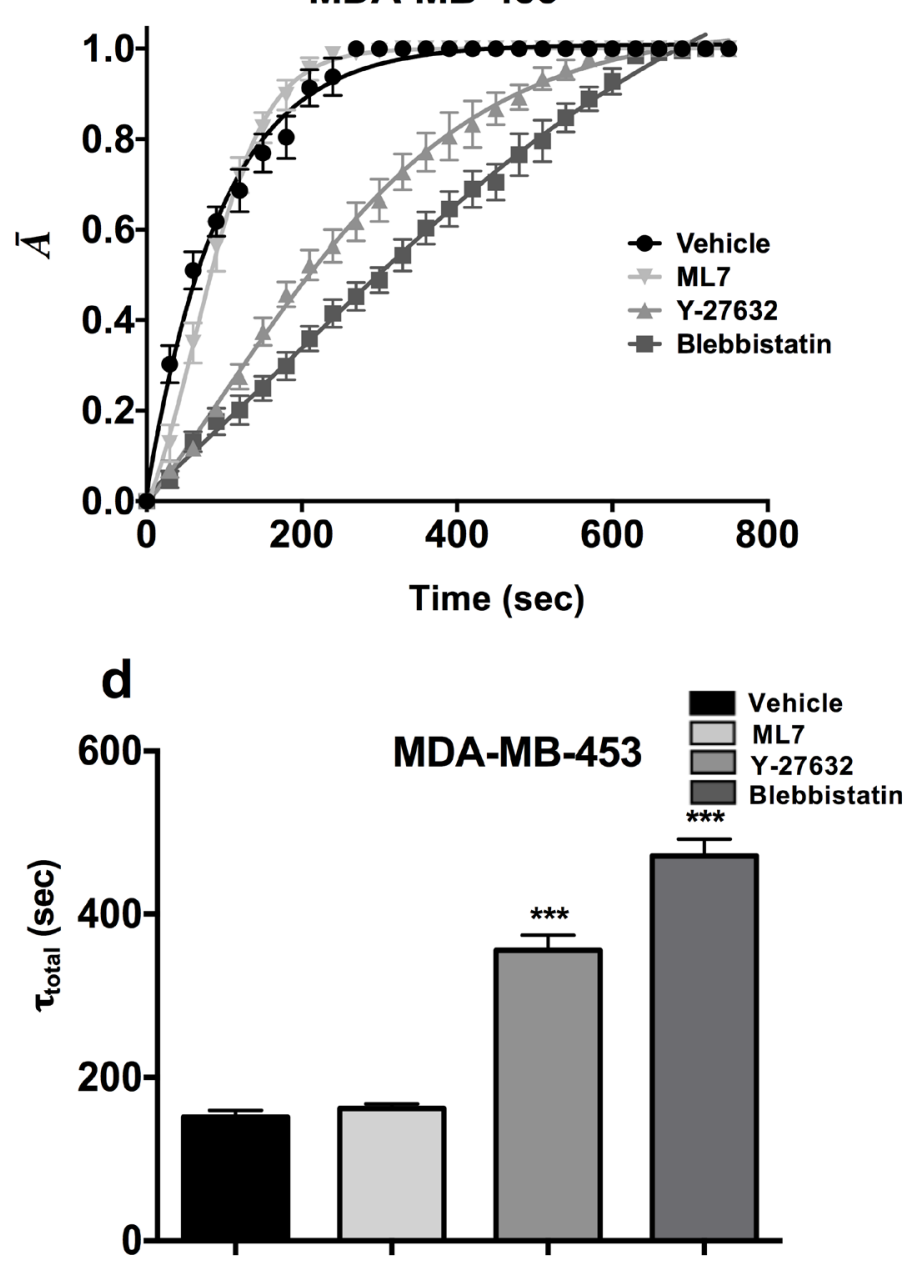

Figure 3: ROCK pathway is essential for maintaining contractility in parental cells. a-b. The parental cells of MCF-7 and MDA-MB-453 treated with Blebbistatin and Y-27632 showed highly significant ablation in the contractile dynamics in both the cell lines, while ML7 treated SDC did not show a significant reduction in contractility MDA-MB-453 cells. c-d. Y-27632 and Blebbistatin treated cells showed a significant increase in the deadhesion time $\left(\tau_{\text {total }}\right)$ as compared to the vehicle treated control in both MCF-7 and MDAMB-453 (**, p value $<0.001)(* * *, p$ value $<0.0001)$. ( $\mathrm{n}=10$ cells per condition). Data is represented as Mean \pm SEM for line graph and Mean + SEM for bar graph. 
not show significant change in degradation between the CSC and parental cells (Figure 5b).

Next we examined if abrogation of cell contractility influences the collagen degradation potential of tumor cells. MCF-7, MDA-MB-453 and MDA-MB-231 cells were treated with the contractility inhibitors (ML7, Y-27632 and Blebbistatin) for 6 hours post seeding and the relative degradation of the collagen was examined. The degradation of collagen in the Y-27632 and Blebbistatin treated MDA-
MB-231 cells was significantly reduced as compared to the control ( $p$ value $<0.0001$ ) (Figure 5c). MDA-MB-453 and MCF-7 cells showed complete abrogation of degradation in Y-27632 and Blebbistatin treated cells (Figure 5d-5e). There was no significant change in the degradation capacity of the ML7 treated cells in MDA-MB-453 (Figure 5d). This indicates that abrogation of the ROCK pathway, and not MLCK pathway, reduced the ECM remodeling potential of tumor cells across all three cell lines tested. a

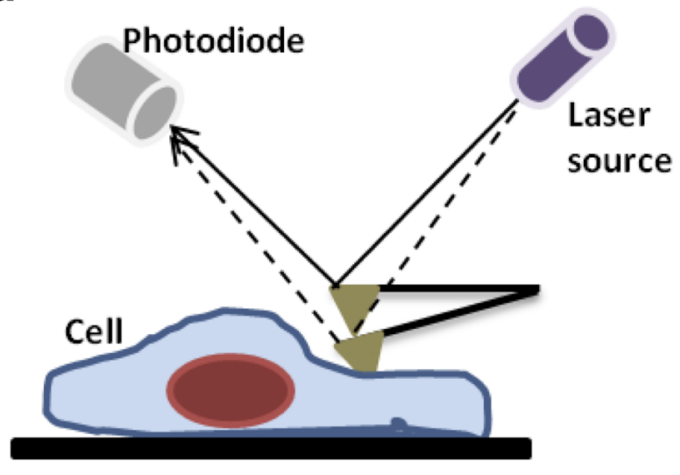

b

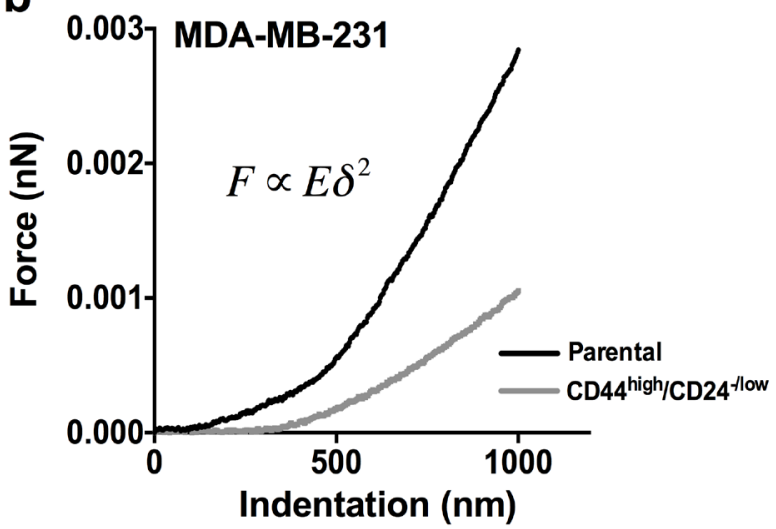

C
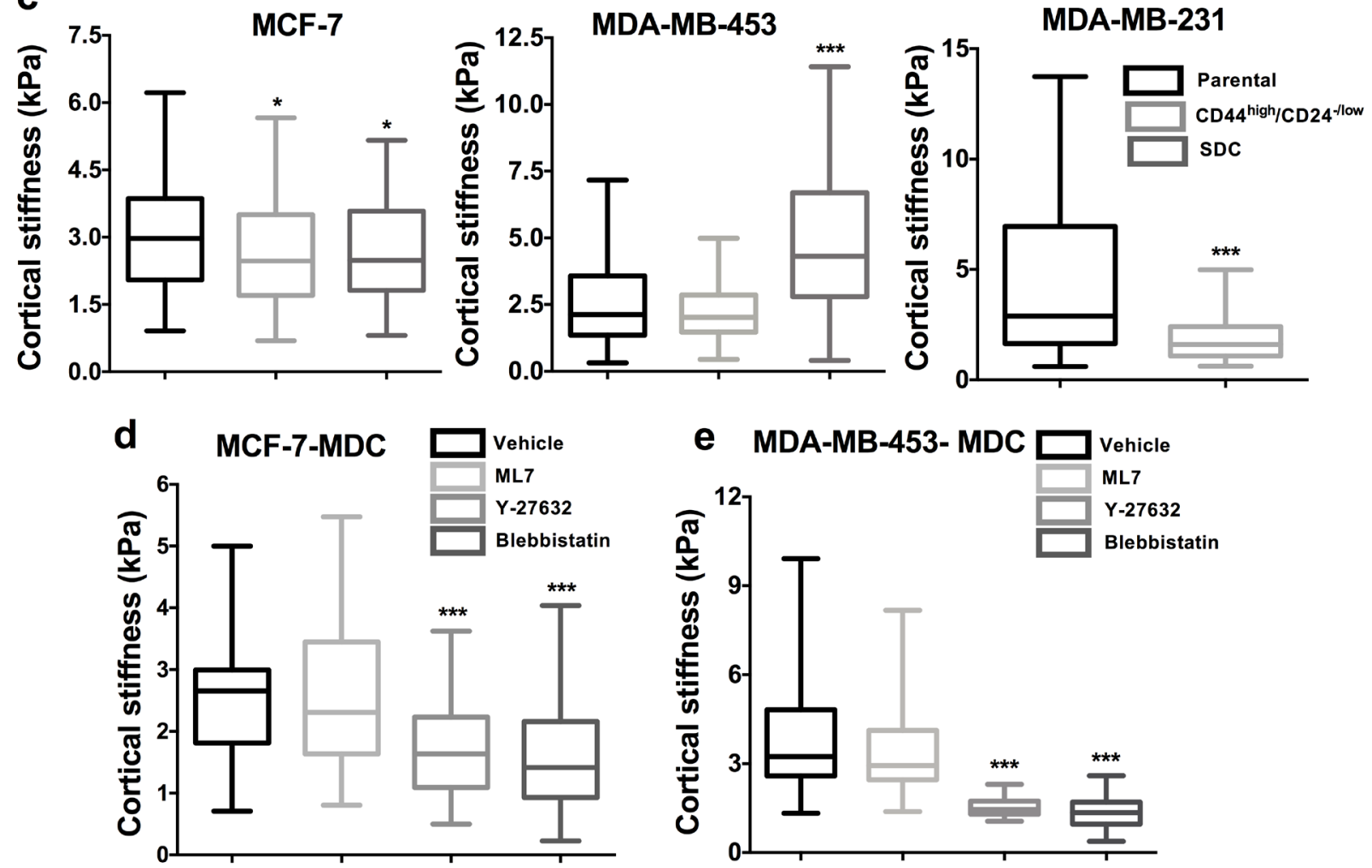

Figure 4: CSCs show differential cortical stiffness compared to parental cells. a. Schematic of indentation of cell by AFM probe to examine cell stiffness. b. Representative force-indentation curves generated by the indentation of parental and CSCs of MDAMB-231. c. Data represents the cortical stiffness of CD44 high $C D 24^{-/ \text {low }}$ cells (MCF-7 and MDA-MB-231, and MDA-MB-453) and SDCs (MCF-7 and MDA-MB-453) compared to the parental population $(\mathrm{n}=100$ cells per condition). d-e. SDCs from MCF-7, and MDAMB-453 were treated with contractility inhibiting drugs ML7, Y-27632 and Blebbistatin and cortical stiffness was quantified using AFM (*, $\mathrm{p}$ value $<0.05)(* *$, p value $<0.001)(* * *$, p value $<0.0001)(\mathrm{n}=50$ cells per condition). Representation: Min to max box plot with median. 


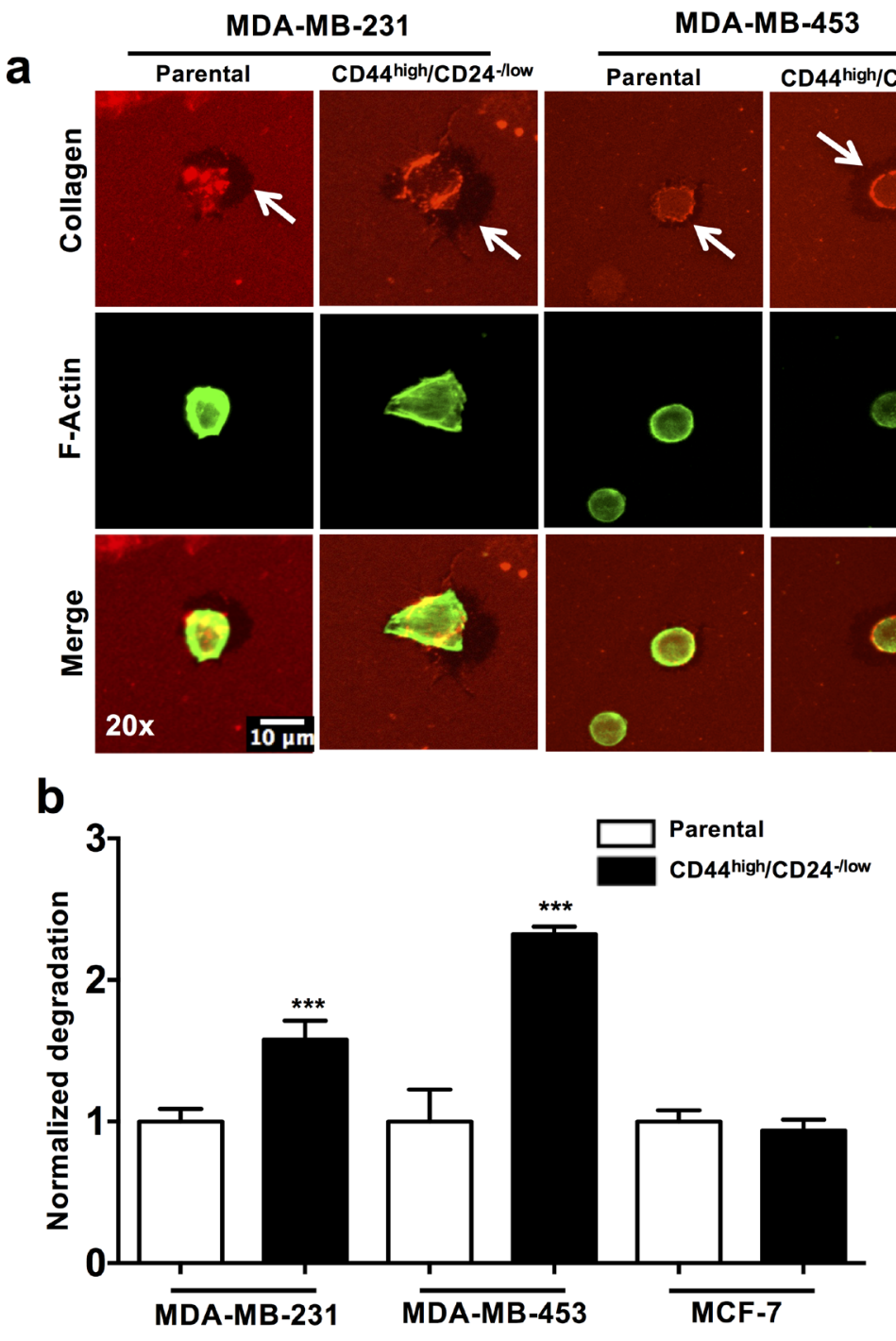

Figure 5: Roles of ROCK pathway in CSCs and parental cells in ECM degrading ability. a. Representative images of collagen (red), F-actin (green) and merged staining from three cancer cells lines are depicted. Arrows indicate the area with degraded collagen. b. Normalized collagen degradation of $\mathrm{CD} 44^{\text {high }} \mathrm{CD} 24^{\text {-llow }} \mathrm{CSCs}$ was quantified keeping parental cell degradation as reference $(n=3)$. c-e. Normalized collagen degradation of parental cells (MDA-MB-231, MDA-MB-453 and MCF-7) was quantified upon treatment with control (vehicle), ML7, Y-27632 and Blebbistatin. $(* \mathrm{p}$ value $<0.05)\left({ }^{* * *} \mathrm{p}\right.$ value $\left.<0.0001\right)(\mathrm{n}=50$ cells per condition). Representation: mean + SEM.

C

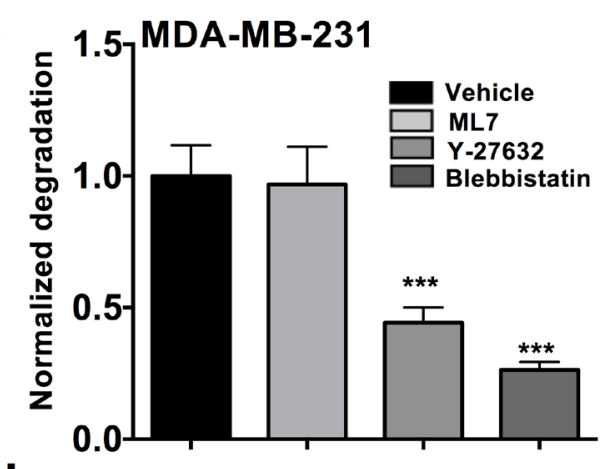

d

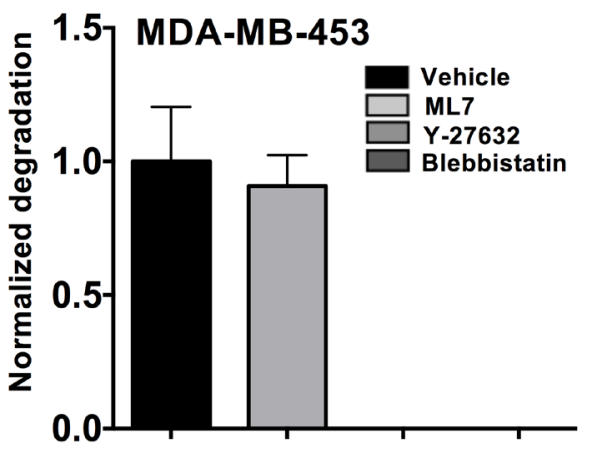

e
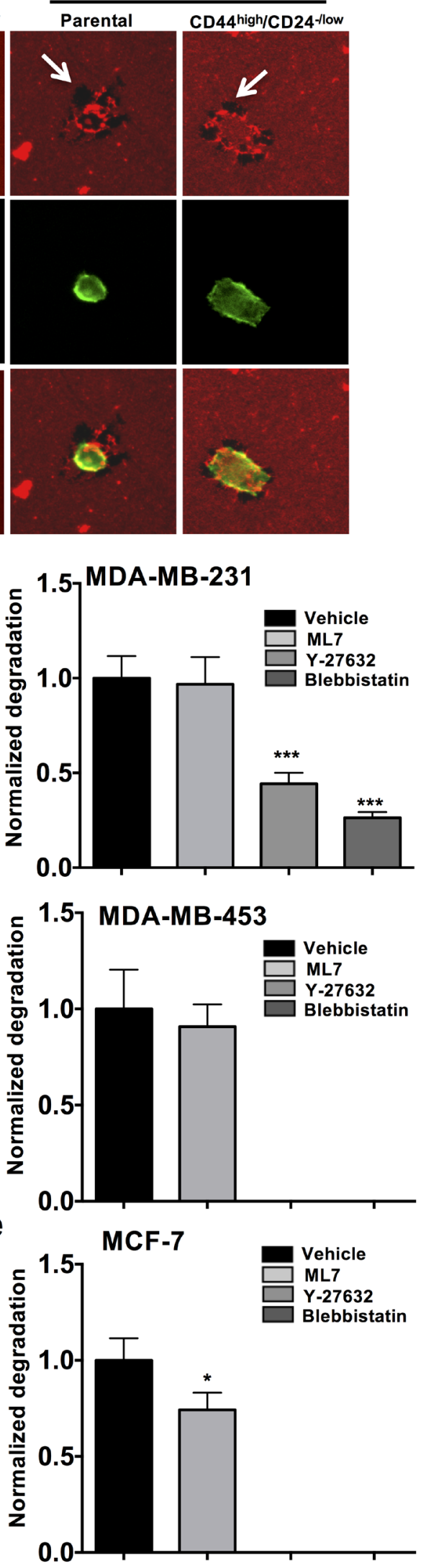


\section{DISCUSSION}

Given the roles of CSCs in metastasis and close association between biophysical properties of the cell and invasiveness, we speculate that CSCs possess altered cytoskeletal organization compared to non-CSCs. Our findings, for the first time, illustrate higher contractile dynamics of CSCs resulting in their increased matrix degradation potential compared with parental cells across two different types of cancers. More importantly, pharmacological inhibition of ROCK pathway abrogates the contractility and collagen degradation potential of both parental cells as well as CSCs, and may be explored as a novel strategy for targeting CSCs as well as bulk tumor population.

As a first step to compare differences in biophysical properties of CSCs and bulk population, we used two distinct methods of enriching CSCs: sorted CD44 $4^{\text {high/ }}$ CD24-low by FACS and SDCs by spheroid assays. There have been several studies describing that $\mathrm{CD} 44^{\text {high/ }}$ CD24-/low population is not the exclusive biomarker for enrichment of pan-CSCs in breast cancer [4, 19-21]. Other CSCs population such as CD133+ and ALDH1+ CSCs contains the non-overlapping CSCs with CD44 high/ $\mathrm{CD} 24^{- \text {llow }}$ population and are known to be phenotypically and functionally different $[22,23]$.

Cell contractility is an important factor in various cellular functions including migration, differentiation and invasion $[12,24,25]$. Seminal work by Totsukawa et al. has illustrated the role of MLCK and ROCK pathways in modulating cell contractility, with MLCK regulating peripheral stress fibers and ROCK regulating central stress fibers [17]. Our results with pharmacological inhibitors of MLCK and ROCK pathways illustrate the prominent role of ROCK pathway in cell contractility, cortical stiffness and ECM degradation of stem-like cells, and are consistent with the upregulation of Rho signaling pathway observed in various cancers [26-28]. Similarly, in fibrosarcoma, cell contractility is described to be indispensable for cell invasion in $3 \mathrm{D}$ matrix, with disruption of contractile machinery inhibiting ECM degradation [29]. Recently, using physiologically relevant 3D cultures, Bissell and co-workers have demonstrated that ROCK inhibition leads to reduction of cell proliferation, and decreased EGFR and integrin signaling leading to suppression of MAPK signaling [30].

Our findings in MDA-MB-231 and MCF-7 cells reveal that CSCs are softer compared to bulk population. Several recent studies have demonstrated the importance of cell stiffness on cell invasion, with cell softening associated with increased metastatic potential [31,32]. However, the increased stiffness of CSCs isolated from MDA-MB-453 cells compared to parental cells can be attributed to the fact that they have been isolated from a melanoma cell line and are functionally different from a breast cancer cell line. Besides contractility and cell stiffness, we examined the cell shape and size of CSCs. Across all the three cell lines tested, stem like cells (sorted and SDCs) were found to be smaller in size than parental cells (Supplementary Figure
1), a factor that might directly help during invasion through dense interstitial matrices [33].

Our results demonstrate important differences in the biophysical properties of CSCs and parental cells, relevant to cancer cell invasion in in vitro settings. Future studies are needed to translate our findings in in vivo models [34]. In addition, drugs targeting the ROCK pathway should be designed in a way that they are not easily effluxed by the drug efflux pump including $\mathrm{ABC}$ transporter system, which are expressed in cancer stem like cells [35-37].

\section{MATERIALS AND METHODS}

\section{Cell culture}

The two breast cancer cell lines (MDA-MB-231 and MCF-7) and a melanoma cell line (MDA-MB-453) were cultured in DMEM High Glucose media (Himedia, India) supplemented with $10 \%$ fetal bovine serum (FBS) and $1 \%$ penicillin-streptomycin antibiotic solution (Gibco, USA). Cells grown were incubated at $37^{\circ} \mathrm{C}$ in a humidified chamber with $5 \% \mathrm{CO}_{2}$.

\section{Enrichment of CSCs (CD44 $\left.4^{\text {high }} / \mathrm{CD} 24^{-/ \mathrm{low}}\right)$ using FACS}

Cells were harvested at $70-80 \%$ confluency and washed twice with ice cold staining buffer (1X PBS with $2 \%$ FBS). The cells were then resuspended in $50 \mu \mathrm{l}$ (per $10^{6}$ cells) of staining buffer and APC anti-CD44 mAb (clone: C26, $20 \mu \mathrm{l} /$ test) and FITC anti-CD24 mAb (clone: ML5, 20 $\mu \mathrm{l} /$ test) ( BD Biosciences, USA) were added and incubated for 30 minutes on ice in dark. Post incubation, cells were washed twice and resuspended in a final volume of $500 \mu$ of staining buffer for sorting using BD FACSAria I (Becton Dickinson, USA). The purity of sorted cells was $>95 \%$. For CD $44^{\text {high/ }}$ CD24-low surface staining analysis, cell were stained, similar to as described for cell sorting, and were analyzed using $\mathrm{BD}$ FACSVerse system (Becton Dickinson, USA). CSCs were enriched based on surface expression of CD44 and CD24, as described previously [38]. The $\mathrm{CD} 44^{\text {high }} / \mathrm{CD} 24^{- \text {-low }}$ cells (CSCs) were sorted from MCF-7 cells and MDA-MB-231 cells. Because MDA-MB-453 cells do not express CD44 on its surface, $\mathrm{CD} 24^{- \text {-low }} \mathrm{CSCs}$ were sorted from these cells.

\section{Spheroid formation assay}

MCF-7 and MDA-MB-453 cells were harvested and seeded onto non-adherent, non-tissue culture treated 6-well plates (Eppendorf, Germany) at a density of 6000 cells/ well. The cells were grown in DMEM/F12 (1:1) serum free media supplemented with $10 \mathrm{ng} / \mathrm{ml}$ basic fibroblast growth factor (bFGF), $20 \mathrm{ng} / \mathrm{ml}$ epidermal growth factor (EGF), Insulin-Transferrin- Selenium (ITS, 10X) and B27 (5X) (all procured from Gibco, USA). The cells grown in these conditions grew as non-adherent, sphere like cluster of cells and were collected on the seventh day post seeding. The 
spheres were dissociated using $0.25 \%$ trypsin as previously described [18] and seeded for various experiments where single cells were required on collagen coated coverslips.

\section{RNA extraction and real time PCR}

Total RNA was extracted from parental and spheroid cells from MCF-7 and MDA-MB-453 using the miRNeasy Mini kit (Qiagen, Germany) following the manufacturer's instructions. Reverse transcription was carried out using the Quantitect Reverse Transcription kit (Qiagen, Germany) using $1 \mu \mathrm{g}$ RNA. The cDNA levels were quantified by Applied Biosystems StepOne Plus (Applied Biosystems, USA) using the SYBR green assay (Quantinova SYBR green PCR mix, Qiagen Germany). Pre-designed primers (Quantitect Primer Assay) specific to the genes of interest were obtained from Qiagen, Germany. The qPCR results were analyzed using StepOne ${ }^{\mathrm{TM}}$ Software v2.3. GAPDH has been used as the endogenous control.

\section{ECM coated glass coverslip preparation}

Glass coverslips (circular: $18 \mathrm{~mm}$ and $12 \mathrm{~mm}$ ) were sterilized using $70 \%$ Ethanol and incubated with rat tail collagen type I $\left(5 \mu \mathrm{g} / \mathrm{cm}^{2}\right)\left(\right.$ Gibco, USA) overnight at $4{ }^{\circ} \mathrm{C}$. Post incubation, the coverslips were blocked with $2 \%$ pluronic (Dow, USA) for 20 minutes and rinsed twice with PBS. Cells were seeded at appropriate seeding densities on the collagen coated coverslips for various assays.

\section{Cell morphology assay}

Cells were seeded onto $18 \mathrm{~mm}$ collagen coated coverslips in duplicates at a seeding density of 1000 cells per well. The cells were fixed 24 hours post seeding with $4 \%$ paraformaldehyde for 20 minutes and washed twice with 1x PBS post fixing. Images of the cells were taken with Olympus 1X71 microscope. Cell area and circularity of the cells was analyzed using ImageJ software.

\section{Collagen degradation assay}

Post blocking of the collagen ( $12 \mathrm{~mm}$ coverslips), the collagen was tagged using Collagen antibody (raised in mouse) (Abcam, UK) at 1:500 dilution for 24 hours at $4{ }^{\circ} \mathrm{C}$. The coverslips were washed with $1 \mathrm{X}$ PBS and incubated with 1:1000 diluted Fluorescence tagged secondary antibody (Donkey anti-rabbit 555) for 2 hours at room temperature as previously described [39]. Post incubation, the coverslips were washed twice with PBS and cells were seeded at a density of 1000 cells per $\mathrm{cm}^{2}$ in triplicates. 6 hours post seeding, the cells were fixed with $4 \%$ paraformaldehyde and washed twice with PBS. Post washing, blocking was done using 1\% BSA for 1 hour at room temperature. F-actin staining was done to visualize the cells using Alexa Fluor 488 Phalloidin antibody at a dilution of 1:500 (in PBS) for 90 minutes at room temperature. Images of the tagged collagen and actin were taken for individual cells on an Olympus 1X71 microscope at 20x magnification. The extent of degradation of the collagen was quantified by thresholding the collagen images using ImageJ software. This was normalized using the cell spread area from the F-actin staining.

\section{Trypsin deadhesion assay}

Cells were seeded at seeding density of 1000 cells/ $\mathrm{cm}^{2}$ on $18 \mathrm{~mm}$ coverslip. The experiment was performed after 24 hours of incubation. The cells were washed with warm PBS $\left(37^{\circ} \mathrm{C}\right)$ and pre-warmed trypsin $(0.25 \%, 500$ $\mu \mathrm{l})$ was then added to the well. Live cell images were captured every 3 seconds using the Olympus 1X71 microscope till the cells rounded up but remained attached to the substrate. For quantifying de-adhesion dynamics, the normalized change in area $(\bar{A})$ was calculated using the formula $\left(\bar{A}=\frac{A_{i}-A_{t}}{A_{i}-A_{f}}\right)$, where $A_{i}$ represents the cell area at time $\mathrm{t}=0, A_{t}$ represents the area at time $\mathrm{t}$, and $A_{f}$ represents the area at the final time point. The experimental deadhesion curves were fitted with the Boltzmann equation $\left(\bar{A}=\frac{1}{1+e^{(t-\tau 1) / \tau 2}}\right)$ to obtain the de-adhesion time constants $\tau_{1}$ and $\tau_{2}$, respectively $\tau_{\text {total }}$ was calculated as the sum of $\tau_{1}$ and $\tau_{2}[7]$

\section{Atomic force microscopy (AFM)}

Cells were seeded on $18 \mathrm{~mm}$ coverslips coated with collagen and allowed to adhere for a minimum of 4 hours. AFM measurements were performed with an Asylum MFP3DAFM (Asylum Research, CA) coupled to a Nikon TE2000E2 epifluorescence microscope. Individual cells were indented using a pyramid-tipped probe (Olympus) with a nominal spring constant of $10 \mathrm{pN} / \mathrm{nm}$. The probe was first calibrated in air using thermal vibration method to determine the exact spring constant. The first $1 \mu \mathrm{m}$ of force-indentation curves for individual cells were fitted with the Hertzian model for a pyramidal tip to obtain estimates of cortical stiffness. At least 100 cells across three experiments were analyzed per condition.

\section{Treatment of cells with contractility inhibitors}

To modulate the contractility of the cells in various experiments, contractility altering drugs including ML7 (Myosin Light Chain Kinase inhibitor) Y-27632 (Rhoassociated protein Kinase inhibitor) and Blebbistatin (a global Non-Muscle Myosin II inhibitor) [40], were used. The drugs were used at the final concentration of $10 \mu \mathrm{M}$ for Blebbistatin and $5 \mu \mathrm{M}$ for Y-27632 and ML7. DMSO was used as the vehicle control.

\section{Statistical analysis}

Statistical analysis for all the experiments was performed using the standard student's t-test. Statistical 
significance was designated based on the $\mathrm{p}$ value as: $* \mathrm{p}$ value $<0.05, * *$ : $\mathrm{p}$ value $<0.001, * * *$ : p value $<0.0001$.

\section{Abbreviations}

ROCK: Rho associated protein kinase; CSC: Cancer stem like cells; AFM: Atomic force microscopy; TNBC: Triple negative breast cancer; ECM: Extra cellular matrix; MMP: Matrix metalloproteinase; MLCK: Myosin light chain kinase; MLC: Myosin light chain; FBS: Fetal bovine serum; DMEM: Dulbecco's modified Eagle's medium; APC: Allophycocyanin; FITC: Fluorescein isothiocyanate; FACS: Fluorescence activated cell sorting; FGF: Fibroblast growth factor; EGF: Epidermal growth factor; ITS: Insulin-Transferrin-Selenium; BSA: Bovine serum albumin; DMSO: Dimethyl sulphoxide; RT-PCR: Reverse transcription polymerase chain reaction; SDC: Spheroid derived single cells; ALDH: Aldehyde dehydrogenase

\section{ACKNOWLEDGMENTS}

The study was supported by grants to RP from Council of Scientific and Industrial Research (CSIR), the Wadhwani Research Foundation, start-up grant of IIT Bombay, and Bristol-Myers Squibb.

\section{CONFLICTS OF INTEREST}

The authors declare no conflicts of interest.

\section{FUNDING}

\begin{tabular}{lcc}
\hline Agency & $\begin{array}{c}\text { Reference } \\
\text { Number }\end{array}$ & PI \\
\hline $\begin{array}{l}\text { Council of Scientific } \\
\text { and Industrial } \\
\text { research (CSIR) }\end{array}$ & 14CSIR008 & Rahul Purwar \\
$\begin{array}{l}\text { Bristol-Myers } \\
\text { Squibb India (BMS) }\end{array}$ & 15BMS001 & Rahul Purwar \\
$\begin{array}{l}\text { Indian Institute of } \\
\text { Technology }\end{array}$ & 13IRCCSG021 & Rahul Purwar \\
$\begin{array}{l}\text { Wadhwani Research } \\
\text { Foundation (WRCB) }\end{array}$ & 15IRSGHC002 & Rahul Purwar \\
\hline
\end{tabular}

\section{Author's contributions}

SS and VA participated in the design of the study, performed the experiments and the statistical analysis, contributed to the interpretation of the results and drafted the manuscript. SM performed the experiments. AD performed the AFM experiments. SD performed the real time PCR and the analysis of the PCR data. SK performed the proliferation assay. SSen and RP contributed to the design of the study, interpretation of the results, statistical analysis and drafting of the manuscript. All authors read and approved the final manuscript.

\section{REFERENCES}

1. Wang R, Lv Q, Meng W, Tan Q, Zhang S, Mo X, Yang X. Comparison of mammosphere formation from breast cancer cell lines and primary breast tumors. J Thorac Dis. 2014; 6:829-37.

2. Wicha MS. Cancer stem cells and metastasis: lethal seeds. Clin Cancer Res. 2006; 12:5606-07. doi: 10.1158/10780432.CCR-06-1537.

3. O'Brien CA, Pollett A, Gallinger S, Dick JE. A human colon cancer cell capable of initiating tumour growth in immunodeficient mice. Nature. 2007; 445:106-10. doi: 10.1038/nature 05372 .

4. Quintana E, Shackleton M, Foster HR, Fullen DR, Sabel MS, Johnson TM, Morrison SJ. Phenotypic heterogeneity among tumorigenic melanoma cells from patients that is reversible and not hierarchically organized. Cancer Cell. 2010; 18:510-23. doi: 10.1016/j.ccr.2010.10.012.

5. Mitra A, Mishra L, Li S. EMT, CTCs and CSCs in tumor relapse and drug-resistance. Oncotarget. 2015; 6:10697711. doi: 10.18632/oncotarget.4037.

6. Radisky DC, Nelson CM. Regulation of mechanical stress by mammary epithelial tissue structure controls breast cancer cell invasion. Oncotarget. 2013; 4:498-99. doi: 10.18632/oncotarget.979.

7. Sen S, Kumar S. Cell-Matrix De-Adhesion Dynamics Reflect Contractile Mechanics. Cell Mol Bioeng. 2009; 2:218-30. doi: 10.1007/s12195-009-0057-7.

8. Khuon S, Liang L, Dettman RW, Sporn PH, Wysolmerski RB, Chew TL. Myosin light chain kinase mediates transcellular intravasation of breast cancer cells through the underlying endothelial cells: a three-dimensional FRET study. J Cell Sci. 2010; 123:431-40. doi: 10.1242/jcs.053793.

9. Kapoor A, Sen S. Synergistic modulation of cellular contractility by mixed extracellular matrices. Int J Cell Biol. 2012; 2012:471591. doi: 10.1155/2012/471591.

10. Samuel MS, Lopez JI, McGhee EJ, Croft DR, Strachan D, Timpson P, Munro J, Schröder E, Zhou J, Brunton VG, Barker N, Clevers H, Sansom OJ, et al. Actomyosin-mediated cellular tension drives increased tissue stiffness and $\beta$-catenin activation to induce epidermal hyperplasia and tumor growth. Cancer Cell. 2011; 19:776-91. doi: 10.1016/j.ccr.2011.05.008.

11. Sood AK, Seftor EA, Fletcher MS, Gardner LM, Heidger PM, Buller RE, Seftor RE, Hendrix MJ. Molecular determinants of ovarian cancer plasticity. Am J Pathol. 2001; 158:1279-88. doi: 10.1016/S0002-9440(10)64079-5.

12. Sadok A, McCarthy A, Caldwell J, Collins I, Garrett MD, Yeo M, Hooper S, Sahai E, Kuemper S, Mardakheh FK, Marshall CJ. Rho kinase inhibitors block melanoma cell migration and inhibit metastasis. Cancer Res. 2015; 75:2272-84. doi: 10.1158/0008-5472.CAN-14-2156. 
13. Haage A, Schneider IC. Cellular contractility and extracellular matrix stiffness regulate matrix metalloproteinase activity in pancreatic cancer cells. FASEB J. 2014; 28:3589-99. doi: 10.1096/fj.13-245613.

14. Matsumura F. Regulation of myosin II during cytokinesis in higher eukaryotes. Trends Cell Biol. 2005; 15:371-77. doi: 10.1016/j.tcb.2005.05.004.

15. Vicente-Manzanares M, Ma X, Adelstein RS, Horwitz AR. Non-muscle myosin II takes centre stage in cell adhesion and migration. Nat Rev Mol Cell Biol. 2009; 10:778-90. doi: $10.1038 / \mathrm{nrm} 2786$.

16. Hindman B, Goeckeler Z, Sierros K, Wysolmerski R. NonMuscle Myosin II Isoforms Have Different Functions in Matrix Rearrangement by MDA-MB-231 Cells. PLoS One. 2015; 10:e0131920. doi: 10.1371/journal.pone.0131920.

17. Totsukawa G, Wu Y, Sasaki Y, Hartshorne DJ, Yamakita Y, Yamashiro S, Matsumura F. Distinct roles of MLCK and ROCK in the regulation of membrane protrusions and focal adhesion dynamics during cell migration of fibroblasts. J Cell Biol. 2004; 164:427-39. doi: 10.1083/jcb.200306172.

18. Ponti D, Costa A, Zaffaroni N, Pratesi G, Petrangolini G, Coradini D, Pilotti S, Pierotti MA, Daidone MG. Isolation and in vitro propagation of tumorigenic breast cancer cells with stem/progenitor cell properties. Cancer Res. 2005; 65:5506-11. doi: 10.1158/0008-5472.CAN-05-0626.

19. Zellmer VR, Zhang S. Evolving concepts of tumor heterogeneity. Cell Biosci. 2014; 4:69. doi: 10.1186/2045-3701-4-69.

20. Campbell LL, Polyak K. Breast tumor heterogeneity: cancer stem cells or clonal evolution? Cell Cycle. 2007; 6:233238. doi: 10.4161/cc.6.19.4914.

21. Ricardo S, Vieira AF, Gerhard R, Leitão D, Pinto R, Cameselle-Teijeiro JF, Milanezi F, Schmitt F, Paredes J. Breast cancer stem cell markers CD44, CD24 and ALDH1: expression distribution within intrinsic molecular subtype. J Clin Pathol. 2011; 64:937-46. doi: 10.1136/jcp.2011.090456.

22. Stuelten CH, Mertins SD, Busch JI, Gowens M, Scudiero DA, Burkett MW, Hite KM, Alley M, Hollingshead M, Shoemaker RH, Niederhuber JE. Complex display of putative tumor stem cell markers in the NCI60 tumor cell line panel. Stem Cells. 2010; 28:649-60. doi: 10.1002/stem.324.

23. Honeth G, Bendahl PO, Ringnér M, Saal LH, GruvbergerSaal SK, Lövgren K, Grabau D, Fernö M, Borg A, Hegardt C. The CD44+/CD24- phenotype is enriched in basal-like breast tumors. Breast Cancer Res. 2008; 10:R53. doi: 10.1186/bcr2108.

24. Swaminathan V, Mythreye K, O'Brien ET, Berchuck A, Blobe GC, Superfine R. Mechanical stiffness grades metastatic potential in patient tumor cells and in cancer cell lines. Cancer Res. 2011; 71:5075-80. doi: 10.1158/00085472.CAN-11-0247.

25. Connell LE, Helfman DM. Myosin light chain kinase plays a role in the regulation of epithelial cell survival. J Cell Sci. 2006; 119:2269-81. doi: 10.1242/jcs.02926.

26. Liu N, Zhang G, Bi F, Pan Y, Xue Y, Shi Y, Yao L, Zhao L, Zheng Y, Fan D. RhoC is essential for the metastasis of gastric cancer. J Mol Med (Berl). 2007; 85:1149-56. doi: 10.1007/s00109-007-0217-y.

27. Fritz G, Just I, Kaina B. Rho GTPases are over-expressed in human tumors. Int J Cancer. 1999; 81:682-87. doi: 10.1002/(SICI)1097-0215(19990531)81:5<682::AIDIJC2>3.0.CO;2-B.

28. Burbelo P, Wellstein A, Pestell RG. Altered Rho GTPase signaling pathways in breast cancer cells. Breast Cancer Res Treat. 2004; 84:43-48. doi: 10.1023/B:BREA.0000018422.02237.f9.

29. Jimenez Valencia $\mathrm{AM}, \mathrm{Wu} \mathrm{PH}$, Yogurtcu ON, Rao P, DiGiacomo J, Godet I, He L, Lee MH, Gilkes D, Sun SX, Wirtz D. Collective cancer cell invasion induced by coordinated contractile stresses. Oncotarget. 2015; 6:43438-51.

30. Matsubara M, Bissell MJ. Inhibitors of Rho kinase (ROCK) signaling revert the malignant phenotype of breast cancer cells in 3D context. Oncotarget. 2016; 7:31602-22.

31. Xu W, Mezencev R, Kim B, Wang L, McDonald J, Sulchek T. Cell stiffness is a biomarker of the metastatic potential of ovarian cancer cells. PLoS One. 2012; 7:e46609. doi: 10.1371/journal.pone.0046609.

32. Lin HH, Lin HK, Lin IH, Chiou YW, Chen HW, Liu CY, Harn HI, Chiu WT, Wang YK, Shen MR, Tang MJ. Mechanical phenotype of cancer cells: cell softening and loss of stiffness sensing. Oncotarget. 2015; 6:20946-58. doi: 10.18632/oncotarget.4173.

33. Li Q, Rycaj K, Chen X, Tang DG. Cancer stem cells and cell size: A causal link? Semin Cancer Biol. 2015; 35:19199. doi: 10.1016/j.semcancer.2015.07.002.

34. Clarke MF, Dick JE, Dirks PB, Eaves CJ, Jamieson CH, Jones DL, Visvader J, Weissman IL, Wahl GM. Cancer stem cells - perspectives on current status and future directions: AACR Workshop on cancer stem cells. Cancer Res. 2006; 66:9339-44. doi: 10.1158/0008-5472.CAN-06-3126.

35. Moitra K. Overcoming Multidrug Resistance in Cancer Stem Cells. BioMed Res Int. 2015; 2015:635745. doi: $10.1155 / 2015 / 635745$.

36. Dean $\mathrm{M} . \mathrm{ABC}$ transporters, drug resistance, and cancer stem cells. J Mammary Gland Biol Neoplasia. 2009; 14:3-9. doi: 10.1007/s10911-009-9109-9.

37. Lee N, Barthel SR, Schatton T. Melanoma stem cells and metastasis: mimicking hematopoietic cell trafficking? Lab Invest. 2014; 94:13-30. doi: 10.1038/labinvest.2013.116.

38. Al-Hajj M, Wicha MS, Benito-Hernandez A, Morrison SJ, Clarke MF. Prospective identification of tumorigenic breast cancer cells. Proc Natl Acad Sci USA. 2003; 100:3983-88. doi: 10.1073/pnas.0530291100.

39. Martin KH, Hayes KE, Walk EL, Ammer AG, Markwell SM, Weed SA. Quantitative measurement of invadopodiamediated extracellular matrix proteolysis in single and multicellular contexts. J Vis Exp. 2012; 2012:e4119.

40. Kovács M, Tóth J, Hetényi C, Málnási-Csizmadia A, Sellers JR. Mechanism of blebbistatin inhibition of myosin II. J Biol Chem. 2004; 279:35557-63. doi: 10.1074/jbc. M405319200. 